\title{
Erratum to: Toxicological profiles of selected synthetic cannabinoids showing high binding affinities to the cannabinoid receptor subtype $\mathbf{C B}_{1}$
}

\author{
Verena J. Koller · Gerhard J. Zlabinger • \\ Volker Auwärter $\cdot$ Sabine Fuchs $\cdot$ Siegfried Knasmueller
}

Published online: 17 May 2013

(C) Springer-Verlag Berlin Heidelberg 2013

\section{Erratum to: Arch Toxicol}

DOI 10.1007/s00204-013-1029-1

Unfortunately, there are some mistakes in the original publication of the article:

(i) The correct version of the last sentence of the abstract is "Since genotoxic effects are in general linear over a wide concentration range and the exposure levels may be higher in epithelial cells than in serum, further experimental work is required to find out whether DNA damage takes place in drug users".

(ii) In Table 1, the forth cannabinoid compound should be JWH-073 (not JWH-018), and in Fig. 5 the unit of the $\mathrm{x}$-axis is $\boldsymbol{\mu} \mathbf{M}$ not $\mathbf{M}$.

The online version of the original article can be found under doi:10.1007/s00204-013-1029-1.

V. J. Koller · S. Knasmueller $(\bowtie)$

Department of Internal Medicine 1, Institute of Cancer Research,

Medical University of Vienna, Borschkegasse 8A,

1090 Vienna, Austria

e-mail: siegfried.knasmueller@meduniwien.ac.at

\section{G. J. Zlabinger}

Center of Pathophysiology, Infectiology and Immunology,

Institute of Immunology, Medical University of Vienna,

Borschkegasse 8A, 1090 Vienna, Austria

\section{Auwärter}

Institute of Forensic Medicine, University Medical Center

Freiburg, Albertstr. 9, 79104 Freiburg, Germany

\section{S. Fuchs}

Christian Doppler-Laboratory for Molecular Biological Food

Analytics, University of Veterinary Medicine,

Veterinärplatz 1, 1210 Vienna, Austria (iii) In the discussion section, it should be stated that "Teske et al. (2010) found after consumption of a cigarette containing $3.6 \mathrm{mg}, 5 \mathrm{~min}$ after consumption, a level of $30 \mathbf{n M}$ with the former drug, in the case of JWH-122, concentrations up to $\mathbf{6 5 0} \mathrm{nM}$ were measured in some individuals (Kneisel and Auwärter 2012). These concentrations are two to three orders of magnitude lower than those which were required to cause toxic effects in the human-derived cell lines which we used in the present study". 